\title{
An Optimization Study of a Hydraulic Gear Pump Cover with Finite Element Method
}

\author{
M. OzSOY ${ }^{a, *}$ And C. KuRnAZ ${ }^{b}$ \\ ${ }^{a}$ Sakarya University, Mechanical Engineering Department, Sakarya, Turkey \\ ${ }^{b}$ HEMA A.S., Research-Development Department, Tekirdag, Turkey
}

\begin{abstract}
In this study, an optimization analysis of the hydraulic gear pump cover with design of experiments and response surface method has been conducted. The sample of the solid cover of a hydraulic pump has been parametrically modelled. Structural strength analysis of the modelled hydraulic pump cover has been realized using finite element method. To prevent the concentration of stress on the hydraulic pump cover and to keep the stress values on the safe side, design inputs were not exceeded. According to the analysis results of this optimization study; the wall thickness of the hydraulic pump cover has been reduced. Finally, experimental tests were performed on hydraulic pump test setup, for verification of the simulation results.
\end{abstract}

DOI: 10.12693/APhysPolA.132.944

PACS/topics: 87.53.Tf, 07.05.Tp

\section{Introduction}

Gear pumps are a type of hydraulic pumps. High pressured gear pumps are chosen when such properties as hydraulic power transfer, basic construction, high capacity, cheapness and easy assembling are required.

Today, as technological development and competition in the industry increase, the working system design is not good enough. The key point of the design is making the best. This means that the designed system should be cheaper and more effective. This can be achieved by optimum system designing and solving the formulation of an optimization problem. An optimization problem searches for the best solution and is characterized by a mathematical function that has a minimum and a maximum value for given boundary conditions.

E. Mucchi, et al. studied simulation of the running external gear pumps. They have modified their old models and created a new model. Authors then prepared a mathematical model and made dynamic simulations. The mathematical model was verified by an experimental study. At the end of the study authors obtained a reduction of $16 \%$ of the running in time [1].

W. Kollek and U. Radziwanowska studied micro pump body mass optimization. They have carried out a static analysis of the body of the micro pump. After analysis of stress and displacement distribution in the pump body, a mass optimization of construction was made. The optimized micro pump body has resulted in more than $30 \%$ increase in energetic efficiency, compared to the original pump [2].

W. Fiebig and M. Korzyb, developed a mathematical model for studying vibration and dynamic loads in external gear pumps. Calculations have been carried out

*corresponding author; e-mail: ozsoy@sakarya.edu.tr using Mathlab/Simulink software. The influence of pressure and rotational speed on the dynamic forces in the bearings has been analysed [3].

P. Osiński et al. studied optimization of volume efficiency of a hydraulic external gear pump after tooth root undercutting. They have carried out several experimental tests for varied number of revolutions. They measured mechanical and volumetric efficiency, mechanical and hydraulic power, moment of losses [4].

H. Shen et al. have carried out a computational fluid dynamic analysis to analyse pressure distribution of internal flow field of the gear pump, and constructed the unidirectional flow-solid coupling model of a gear, to acquire the contact stress of tooth surface, using Ansys workbench software [5].

P. Casoli et al. have carried out an optimisation study of an external gear pump. They used a software developed by the University of Parma for analysis and optimization of gear pumps. The procedure is based on a path search method, known as steepest descent, which optimizes the considered parameters, starting from a design, taken as the initial reference. The objective functions, defined for the optimization, permit to account for the volumetric efficiency, the delivery pressure ripple and the maximum and minimum pressure peaks during the meshing process [6].

S. Wang et al. studied the instantaneous pressure of the meshing action in the external gear pumps and motors. The study employed the optimization theorem to analyse the nonlinear dynamical equations, to define the instantaneous flow area, overlapped by the wear-plate profiles and control volumes [7].

Noorpoor, modelled and simulated a gear oil pump, used in a diesel engine, and carried out its fluid flow analysis using a solver. The optimization and redesign of the pump has been discussed and then the outcomes have been compared with the experimental and previous results. The strategy used here consisted in using 
dynamic meshes, dividing a tooth rotating cycle into a certain number of time steps, investigating the flow and getting the results for each time step [8].

P. Stefanov used multi-objective optimization method for operational planning of power systems [9]. M. Kan studied optimization of channel angle of heat exchangers [10].

In this study, after the literature review, first, the pump cover will be designed and a static structural analysis will be performed. Then an optimization will be carried out, using the results of the static analysis, and several candidates will be obtained. Finally, the best of the candidates will be chosen as the final design. At last, the confirmation tests will be conducted and the results will be compared with the unoptimized geometry.

\section{Design and analysis}

The geometric model of the pump cover was created in Ansys Design Modeler module, which is a part of ANSYS, for creating geometric models (Fig. 1). Geometry was parametrically modelled as a solid object. Thickness values of the pump cover $t_{1}$ and $t_{2}$ were used as the parameters (Fig. 2).
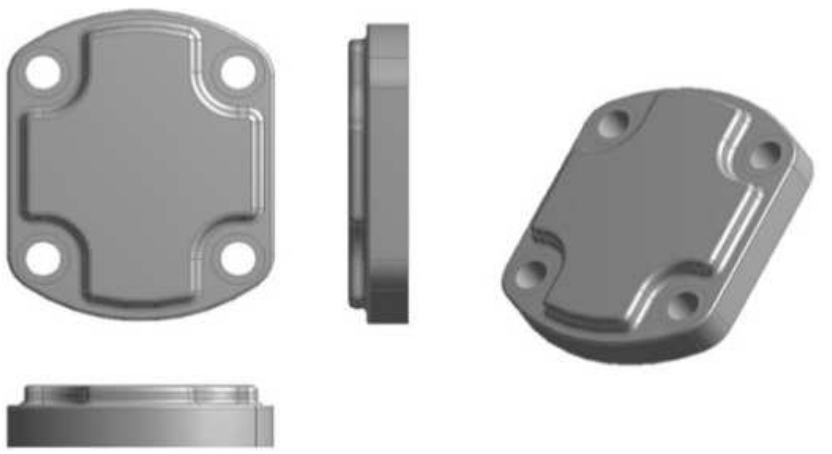

Fig. 1. Geometric model of the pump cover.

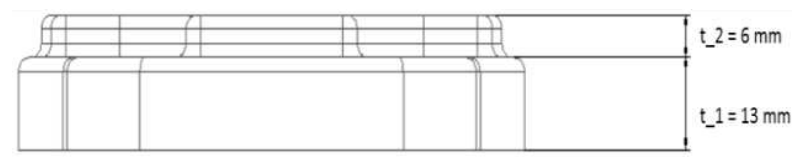

Fig. 2. Parameters of the pump cover.

Static analysis of the pump cover was done with Ansys Workbench Mechanical Module, using finite element method. GGG 50 was chosen as the material of pump cover, according to ISO EN 1563.

For static tests, the surface of holes, which connect body and cover by bolt and nut connections was chosen as the fixed support (Fig. 3a) and a pressure of 280 bar was applied to the region of the cover, which is exposed to pressure during running conditions (Fig. 3b).
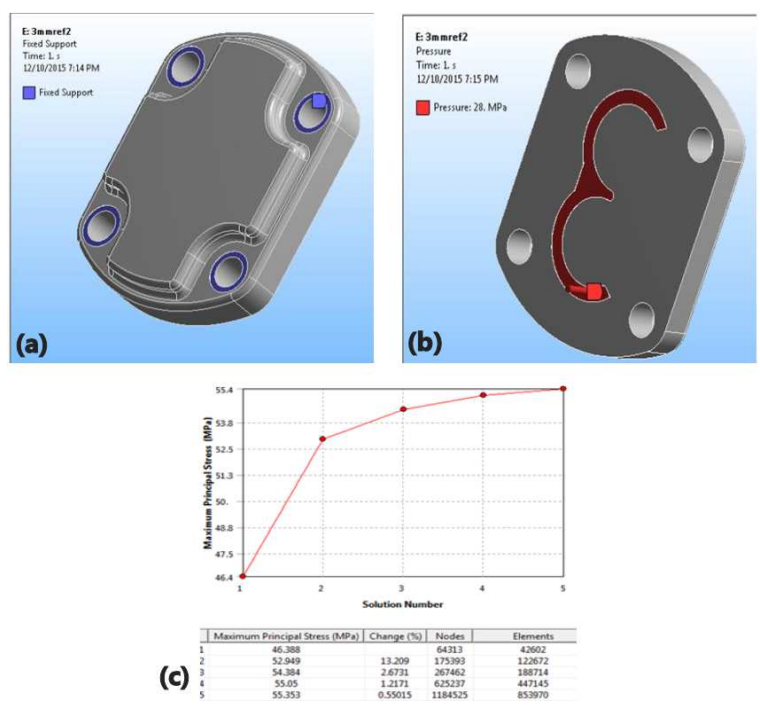

Fig. 3. (a) Boundary conditions, (b) loading conditions, (c) mesh optimization.

Firstly a $3 \mathrm{~mm}$ mesh was applied, after that the mesh was increased automatically, as a part of mesh optimization process, until the difference between the results reached $1 \%$ (Fig. 3c). The results of the static structural analysis are shown in Fig. 4.
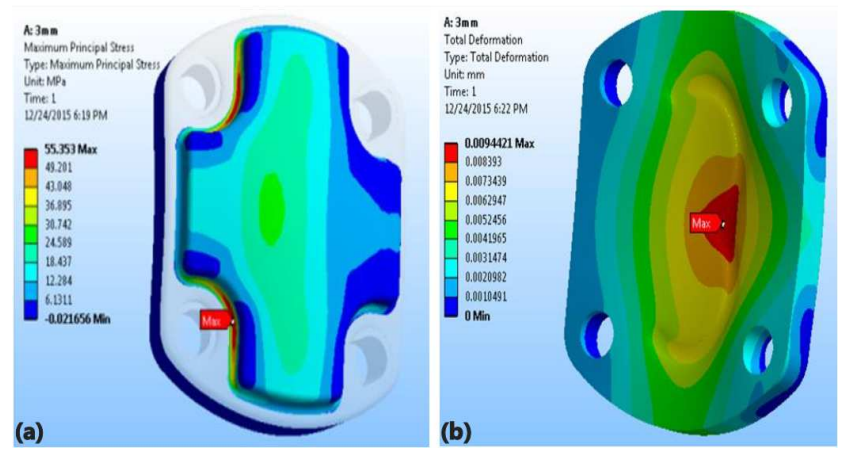

Fig. 4. (a) Maximum principal stress, (b) maximum displacement.

After the static structural analysis with optimized mesh, the obtained values of maximum principal stress and maximum deflection were $55.353 \mathrm{MPa}$ and $0.009 \mathrm{~mm}$, as shown in Fig. 4a and b.

\section{Mass optimization}

Parametric solid model of the cover was modelled in Ansys Design Modeler module and stress, displacement analysis were conducted in Mechanical module. After running a static structural analysis, the mass optimization was done. Optimization in ANSYS was carried out in the Design Explorer. In this method, first DOE (design of experiments), then response surface method and finally optimization were applied. 
In this study, there are two inputs, two outputs and two boundary conditions. The inputs are the geometric dimensions $\left(t_{1}\right.$ and $\left.t_{2}\right)$, the outputs are the results of the static structural analysis, (maximum displacement and maximum principal stresses) and boundary conditions are the acceptable maximum displacement and the acceptable maximum principle stress.

\subsection{Design of experiments}

This is the first step of optimisation study in Ansys Design Explorer. Basically, DOE is a scientific way to conduct a series of experiments with a given set of parameters, each with a range, that minimizes the number of runs needed to understand the influence of the parameters [11]. In this study Central Composite Design type of DOE was used [11].

$$
n=2^{k}+2 k+n_{0} \text {. }
$$

In this method $n$ is the total number of designs, $k$ is the number of input (design) variables and $n_{0}$ is the count of central point. In this study, $k=2$, and $n_{0}=1$, so $n=4+4+1=9$.

Parameters $t_{1}$ and $t_{2}$ that define geometric thicknesses are inputs of this step. The outputs are the maximum displacements and the maximum principal stresses and the solid mass of each of the design points. The summary of parameters used in the design can be seen in Table I. At the end of this step the desired number of candidates will be obtained within the range of the entered parameters (Table II).

TABLE I

Information about parameters.

\begin{tabular}{c|c}
\hline \hline $\begin{array}{c}\text { Parameter name } \\
\text { in the software }\end{array}$ & Parameter \\
\hline P95 (input) & $t_{1}$ thickness \\
P96 (input) & $t_{2}$ thickness \\
P97 (output) & Max. total deformation \\
P98 (output) & Solid mass \\
P99 (output) & Max. principal stress
\end{tabular}

TABLE II

Boundaries of DOE.

\begin{tabular}{c|c|c}
\hline \hline Design variables & $t_{1}[\mathrm{~mm}]$ & $t_{2}[\mathrm{~mm}]$ \\
\hline Lower bound & 8 & 2 \\
Upper bound & 13 & 6
\end{tabular}

After the design of the experiments, nine candidates were obtained. Design point 1 (DP1) is the original model. The information on these candidates is shown in Table III.

\subsection{Response surface methodology}

This is the second step of optimisation. Response surface methodology is a collection of mathematical and statistical techniques for empirical model building. By careful design of experiments, the objective is to optimize a
TABLE III

Candidates of DOE.

\begin{tabular}{c|c|c|c|c|c}
\hline \hline $\begin{array}{c}\text { Design } \\
\text { point }\end{array}$ & $\begin{array}{c}\text { P95 } \\
{[\mathrm{mm}]}\end{array}$ & $\begin{array}{c}\text { P96 } \\
{[\mathrm{mm}]}\end{array}$ & P97 [mm] & P98 [kg] & P99 [Mpa] \\
\hline DP1 & 13 & 6 & 0.009421 & 0.83254 & 55.353 \\
DP2 & 10.5 & 4 & 0.014887435 & 0.64535934 & 61.93347353 \\
DP3 & 8 & 4 & 0.023064323 & 0.52104023 & 97.35722054 \\
DP4 & 13 & 4 & 0.010790647 & 0.76967845 & 47.39358345 \\
DP5 & 10.5 & 2 & 0.018348906 & 0.583563789 & 51.57584608 \\
DP6 & 10.5 & 6 & 0.012418823 & 0.708225264 & 74.7139659 \\
DP7 & 8 & 2 & 0.030991121 & 0.459244679 & 79.36836096 \\
DP8 & 13 & 2 & 0.01258344 & 0.7078829 & 36.52307848 \\
DP9 & 8 & 6 & 0.017907558 & 0.583906153 & 111.1403412
\end{tabular}

response (output variable) which is influenced by several independent variables (input variables). An experiment is a series of tests, called runs, in which changes are made in the input variables in order to identify the reasons for changes in the output response [12]. Minimums and maximums of the design points can be seen in Table IV.

TABLE IV

Minimums and maximums of output parameters.

\begin{tabular}{c|c|c|c|c|c}
\hline \hline Name & $\begin{array}{c}\text { P95 } \\
{[\mathrm{mm}]}\end{array}$ & $\begin{array}{c}\text { P96 } \\
{[\mathrm{mm}]}\end{array}$ & $\begin{array}{c}\text { P97 } \\
{[\mathrm{mm}]}\end{array}$ & $\begin{array}{c}\text { P98 } \\
{[\mathrm{kg}]}\end{array}$ & $\begin{array}{c}\text { P99 } \\
{[\mathrm{MPa}]}\end{array}$ \\
\hline Output parameter & 13 & 6 & 0.0094421 & 0.83254 & 55.799 \\
minimums & 8 & 2 & 0.030991 & 0.45924 & 80.06 \\
& 13 & 2 & 0.012583 & 0.70788 & 36.813 \\
\hline Output parameter & 8 & 2 & 0.030991 & 0.45924 & 80.06 \\
maximums & 13 & 6 & 0.094421 & 0.83254 & 55.799 \\
& 8 & 6 & 0.017908 & 0.58391 & 111.38
\end{tabular}

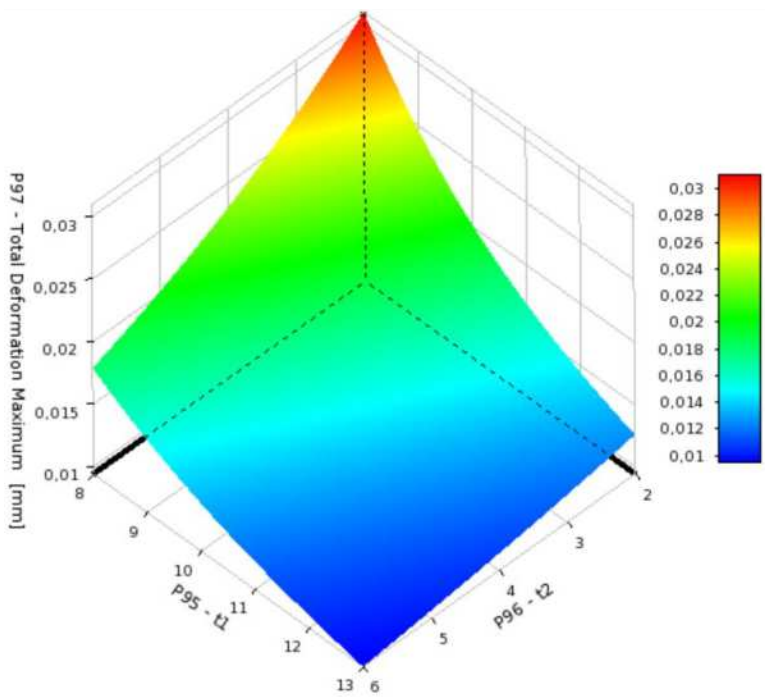

Fig. 5. Total deformation as function of $t_{1}$ and $t_{2}$ parameters.

Figures 5 and 6 show total deformations and maximum principal stresses as functions of $t_{1}$ and $t_{2}$ input parameters. 


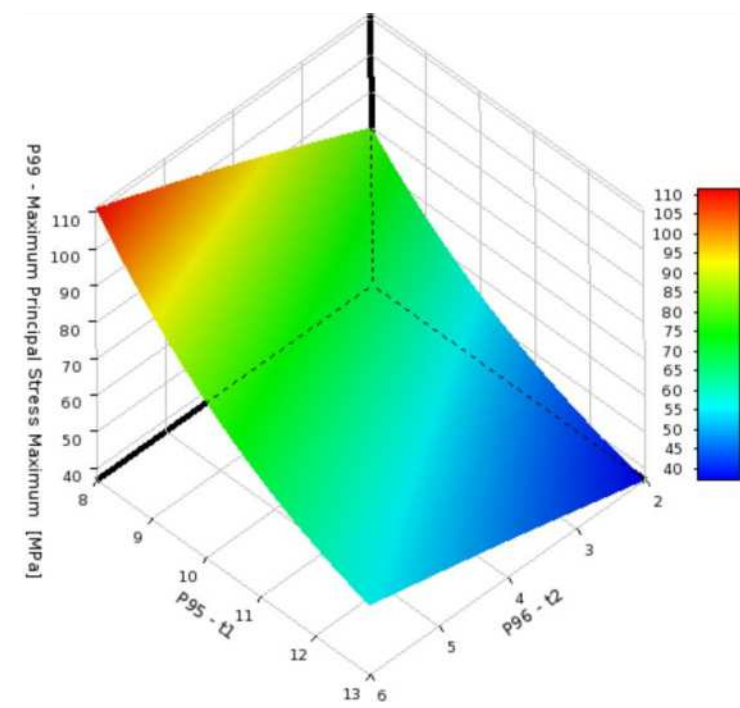

Fig. 6. Maximum principal stresses as function of $t_{1}$ and $t_{2}$ parameters.

\subsection{Optimization}

This is the last step of the study for finding the best candidate, or candidates. Two boundaries were applied to the problem. These are, the maximum displacement of $0.025 \mathrm{~mm}$ and the maximum principle stress of $150 \mathrm{MPa}$, that can occurred in the model. Using these constraints, the candidate with the lowest mass of the part, or a number of candidates will be found. Three best candidates were found in this study (Table V). Finally, the candidate A was selected for manufacturing (Fig. 7).

TABLE V

Candidates of optimization.

\begin{tabular}{c|c|c|c|c|c}
\hline \hline Candidate & $\begin{array}{c}t_{1} \\
{[\mathrm{~mm}]}\end{array}$ & $\begin{array}{c}t_{2} \\
{[\mathrm{~mm}]}\end{array}$ & $\begin{array}{c}\text { Total } \\
\text { deformation } \\
{[\mathrm{mm}]}\end{array}$ & $\begin{array}{c}\text { Max. } \\
\text { principal } \\
\text { stress } \\
{[\mathrm{Mpa}]}\end{array}$ & $\begin{array}{c}\text { Mass } \\
{[\mathrm{kg}]}\end{array}$ \\
\hline $\mathrm{A}$ & 8.9625 & 2.0489 & 0.0246 & 66.878 & 0.5086 \\
$\mathrm{~B}$ & 8.5825 & 2.7208 & 0.0244 & 77.082 & 0.51036 \\
$\mathrm{C}$ & 8.2525 & 3.1895 & 0.0245 & 85.830 & 0.50842
\end{tabular}

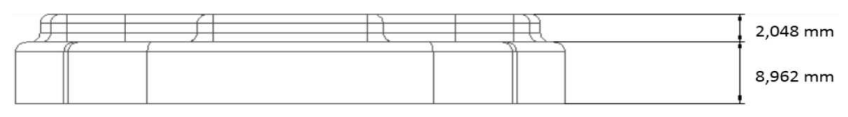

Fig. 7. Best optimization candidate.

\section{Experimental study}

Static life and performance tests of pump cover were conducted in order to confirm the optimization results.

Performance tests of the covered pump were carried out under fixed conditions. Such parameters, as pressure, temperature and efficiency, were measured. After that, static life tests were made and again the performance test was conducted. The efficiency values before and after the static life test were compared. It was determined, whether the pump had any functional loss in fixed conditions. Pump cover surface was examined for cracks or breakage deformation, for confirmation.

Efficiency values before the static life tests are seen in Fig. 6. The curves were derived from the performance tests conducted under 1000, 1500 and $3000 \mathrm{rpm}$, during time of 120 seconds, from zero pressure to maximum pressure.

In static life tests the whole pump with the cover of optimum thickness was tested under maximum pressure of 280 bar until the number of $10^{7}$ cycles was reached. Efficiency values, before and after static tests can be seen at Figs. 8 and 9.

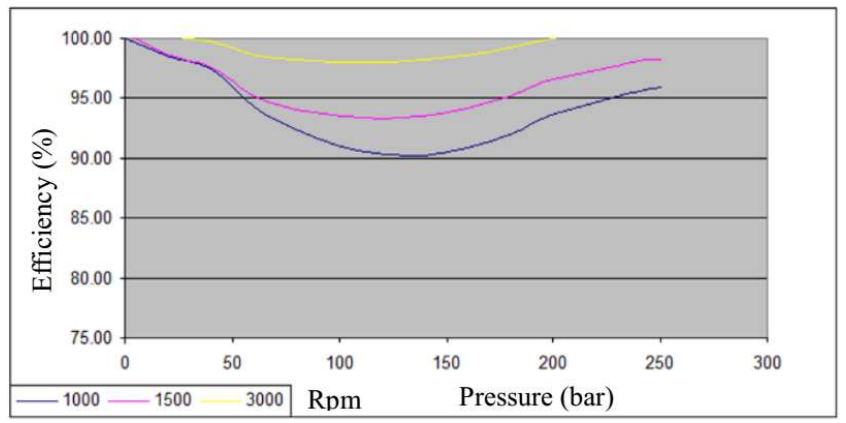

Fig. 8. Efficiency values before static tests.

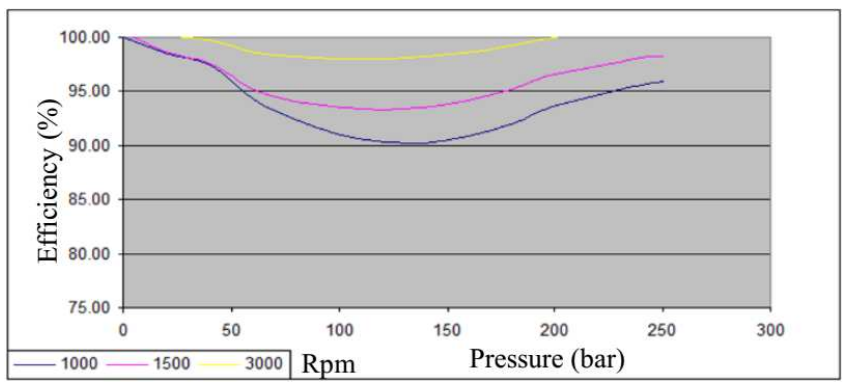

Fig. 9. Efficiency values after static tests.

\section{Confirmation tests}

Surface control was conducted by liquid penetrant examination method. First crack control was made in the middle of the static life test (after $5 \times 10^{5}$ cycles). No cracks were observed, so the test was continued. Last control was made after static life and performance test. No deformation was observed on pump cover, as result of static life tests, based on hand, eye and liquid penetrant examination methods (Fig. 10).

\section{Conclusions}

In this study experimental tests were made after finite element analysis and optimization work. Experimental tests covered static life and functional tests. Efficiency 


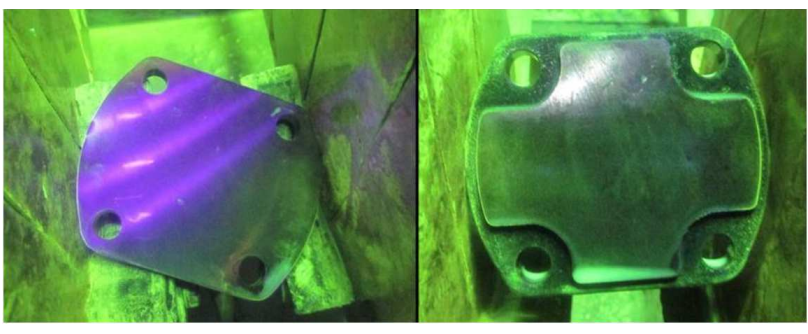

Fig. 10. Surface crack control.

values derived from performance tests, conducted before and after the static life tests, were compared. It was observed that the efficiency loss was $10 \%$ of the allowed difference value. Changing of the cover thickness was inside the allowed conditions.

Visual and liquid penetrant method was used for the physical control, after the experimental tests. Since no cracks were observed after the examinations, the optimization study was confirmed. The starting and the optimized values of hydraulic pump cover are given in Table VI.

TABLE VI

Starting values and values after mass optimization study.

\begin{tabular}{c|c|c|c|c|c}
\hline \hline & $\begin{array}{c}t_{1} \\
{[\mathrm{~mm}]}\end{array}$ & $\begin{array}{c}t_{2} \\
{[\mathrm{~mm}]}\end{array}$ & $\begin{array}{c}\text { Principal } \\
\text { stress } \\
{[\mathrm{MPa}]}\end{array}$ & $\begin{array}{c}\text { Maximum } \\
\text { displacement } \\
{[\mu \mathrm{m}]}\end{array}$ & $\begin{array}{c}\text { Weight } \\
{[\mathrm{g}]}\end{array}$ \\
\hline $\begin{array}{c}\text { Beginning } \\
\text { position }\end{array}$ & 13 & 6 & 55.353 & 9 & 832 \\
$\begin{array}{c}\text { Optimization } \\
\text { position }\end{array}$ & 8.97 & 2.05 & 66.878 & 25 & 508
\end{tabular}

According to the optimization results the thickness of the hydraulic gear pump cover was changed. The new manufactured cover was verified. In the future our aim is to develop new pumps by making the thickness optimization of the pump body and pump front cover, with minimum material waste.

\section{Acknowledgments}

Authors thank the Research and Development Department of HEMA A.S. for valuable support.

\section{References}

[1] E. Mucchi, G. D'Elia, G. Dalpiaz, Meccanica 47, 621 (2012).

[2] W. Kollek, U. Radziwanowska, Arch. Civil Mech. Engin. 15, 109 (2015).

[3] W. Fiebig, M. Korzyb, Arch. Civil Mech. Engin. 15, 680 (2015).

[4] P. Osiński, A. Deptuła, M.A. Partyka, Arch. Civil Mech. Engin. 13, 422 (2013).

[5] H. Shen, Z. Li, L. Qi, L. Qiao, Mech. Syst. Signal Proc. 99, 921 (2018), in press.

[6] P. Casoli, A. Vacca, G.L. Berta, Optimization of Relevant Design Parameters of External Gear Pumps, in: Proc. 7th JFPS Int. Symp. Fluid Power, Toyama, Japan 2008.

[7] S. Wang, H. Sakurai, A. Kasarekar, IEEE/ASME Trans. Mechatronics 16, 945 (2011).

[8] A.R. Noorpoor, Int. J. Automotive Engineering 3, 496 (2013).

[9] P. Stefanov, A. Savić, G. Dobrić, Acta Phys. Pol. A 128, B-138 (2015).

[10] M. Kan, O. Ipek, B. Gurel, Acta Phys. Pol. A $\mathbf{1 2 8}$ B-49 (2015).

[11] Y.Y. Perng, J. Will, Optimization in ANSYS Workbench, Ansys INC., 2011.

[12] L. Alvarez, Ph.D. Thesis, University of Bradford, 2000 . 